\title{
MộT SỐ YẾU TỐ NGUY Cơ LIÊN QUAN ĐẾN TỬ VONG Ở BỆNH NHI VIÊM PHỔI NĂNG DO ADENOVIRUS TẠI KHOA ĐIỀU TRI TÍCH CỨC BỂNH VIỆN NHI TRUNG ƯƠNG
}

\author{
Nguyễn Thị Mai Thùy', Tạ Anh Tuấn², Đậu Việt Hùng²
}

\section{TÓM TẮT}

Muc tiêu: Adenovirus là một trong những nguyên nhân gây viêm phổi nặng ở trẻ em với tỷ lệ tử vong cao. Mục tiêu của nghiên cứu xác định các yếu tố nguy cở tử vong ở bệnh nhân viêm phổi nặng do nhiểm Adenovirus. Đối tượng và phương pháp nghiên cứu: Đây là nghiên cứu mô tả, các bệnh nhân được chẩn đoán viêm phổi nặng do nhiễm Adenovius tại khoa ĐTTC bệnh viện Nhi Trung ương sẽ được lấy vào nghiên cứu, thời gian từ 11/2016 đến 06/2018. Các đặc điểm lâm sàng, cận lâm sàng và tử vong của bệnh nhân được phân tích đơn biến, sau đó sử dụng phân tích đa biến để xác định yếu tố nguy cơ. Kết quả: Trong nghiên cứu có 90 bệnh nhân đủ tiêu chuẩn, có 30 bênh nhân tử vong, chiếm tỷ lê 33,3\%. Sốc nhiễm khuẩn $(\mathrm{OR}=2,8 ; 95 \% \mathrm{CI}$ : $1,89-4,04)$; suy dinh dương (OR=3,41;95\%CI: 1,29-9,02); gan to $(\mathrm{OR}=8,64 ; 95 \% \mathrm{CI}: 2,89-25,8)$; viêm phổi rất nặng ( $\mathrm{OR}=1,7 ; 95 \% \mathrm{CI}: 1,4-2,08)$; biến chứng viêm phổi kẽ $(O R=7,5 ; 95 \% C I: 2,77-20,33)$; giảm bạch cầu theo tuổi (OR= 4; 95\%CI: 1,2-13,6), tăng bạch câu theo tuổi (OR=4,6;95\%CI: $1,4-15,0)$, giảm bạch cầu lympho theo tuổi $(\mathrm{OR}=5,8 ; 95 \% \mathrm{CI}$ : 1,4- 24,3), $\mathrm{Hb}<100 \mathrm{~g} / \mathrm{l}(\mathrm{OR}=8,7 ; 95 \% \mathrm{CI}: 1,9-40,03)$, Albumin $\leq 35 \mathrm{~g} / \mathrm{l}(\mathrm{OR}=16,8 ; 95 \% \mathrm{CI}: 2,1-131,9)$, tình trang rối loạn oxy hóa P/F < 200 (OR=11,3; 95\%CI: 1,4 90,9); Lactat > 2,5 (OR= 3,4;95\%CI: 1,26-9,2) là những yếu tố làm tăng nguy cơ tử vong ở bệnh nhân viêm phổi nặng nhiễm Adenovirus. Từ phân tích hồi quy đa biến logistic thu được kết quả: các yếu tố độc lập làm tă̆ng nguy có tử vong ở bệnh nhân viêm phổi nặng nhiếm Adenovirus là: tình trạng gan to $(\mathrm{OR}=$ 8,4; 95\%CI: 1,66 - 43,4); giảm bạch câu theo tuổi $(\mathrm{OR}=11,9 ; 95 \% \mathrm{CI}: 1,2-120,7)$. Kết luận: Tỷ lệ tử vong của nhóm nghiên cứu là $33,3 \%$. Gan to và giảm bạch câu theo tuối là những yếu tố làm tăng nguy cơ tử vong ở bệnh nhân viêm phổi nặng nhiễm Adenovirus.

Tư khóa: Adenovirus, trẻ em, viêm phổi, yếu tố nguy cơ

\section{SUMMARY \\ RISK FACTORS ASSOCIATED WITH MORTALITY RATE FOR SEVERE ADENOVIVUS PNEUMONIA IN PICU OF THE NATIONAL CHILDREN HOSPITAL}

\footnotetext{
${ }^{1}$ Trường Đại học Y Hà nội

²Bệnh viện Nhi Trung ương

Chịu trách nhiệm chính: Tạ Anh Tuấn

Email: drtuanpicu@gmail.com

Ngày nhận bài: 19.10.2020

Ngày phản biện khoa học: 26.11.2020

Ngày duyệt bài: 8.12.2020
}

Aims: Adenoviruse is an important pathogen of severe pneumonia in children. The study aimed to assess risk factors and outcomes with severe Adenovirus pneumonia. Methods: This cross sectional descriptive study was conducted at the Pediatric Intensive Care Unit of the National Children Hospital from $11 / 2016$ to $06 / 2018$. All patients with confirmed diagnosis of severe Adenovirus pneumonia were included in the study. The characteristics and outcomes of the patients were compared using $\chi^{2}$ test. Logistic regression analysis was performed to identify risk factors. Results: 90 patients with Adenovirus severe pneumonia were studied, mortality rate was $33,3 \%$. Septic shock (OR= 2,8; 95\%CI: 1,894,04), malnutrition ( $\mathrm{OR}=3,41 ; 95 \% \mathrm{CI}: 1,29-9,02)$, hepatomegaly $(\mathrm{OR}=8,64 ; 95 \%$ CI: 2,89$25,8)$, severe pneumonia (OR=1,7; 95\%CI: 1,4 $2,08)$, interstitial pneumonia ( $\mathrm{OR}=7,5 ; 95 \% \mathrm{CI}: 2,77-$ $20,33)$, neutropenia $(\mathrm{OR}=4 ; 95 \% \mathrm{CI}: 1,2-13,6)$, leucocytosis (OR=4,6; 95\%CI: 1,4-15,0), lymphopenia ( $\mathrm{OR}=5,8 ; 95 \% \mathrm{CI}: 1,4-24,3), \mathrm{Hb}<100$ $\mathrm{g} / \mathrm{l}(\mathrm{OR}=8,7 ; 95 \% \mathrm{CI}: 1,9-40,03)$, Albumin $\leq 35 \mathrm{~g} / \mathrm{l}$ $(\mathrm{OR}=16,8 ; 95 \% \mathrm{CI}: 2,1-131,9), \mathrm{P} / \mathrm{F}<200$ (OR= 11,3; 95\%CI: 1,4 - 90,9), Lactat > 2,5 (OR= 3,$4 ; 95 \%$ CI: $1,26-9,2$ ) are factors that increase the risk of death in patients with severe adenovirus pneumonia.After using logistic regression analysis show the independent factors that predict the risk of death arehepatomegaly $(\mathrm{OR}=8,4 ; 95 \% \mathrm{CI}: 1,66-$ $43,4)$; neutropenia $(\mathrm{OR}=11,9 ; 95 \% \mathrm{CI}: 1,2-120,7)$. Conclusion: Mortality rate is high for severe Adenovirus pneumonia in children. Hepatomegaly and leucopenia are factors that increase the risk of death in patients with severe Adenovirus-associated pneumonia factor

Keywords: Adenovirus, children, pneumonia, risk

\section{I. ĐĂT VẤN ĐỀ}

Viêm phổi là bệnh rất hay gặp ở trẻ em do nhiều nguyên nhân, tuy nhiên vi rút có thể chiếm tới 80 - 85\% số căn nguyên ở trẻ em [1], trong đó Adenovirus là một trong những tác nhân chính [2] với tỷ lệ tử vong cao [3]. Trong năm vừa qua tại khoa Điêuu trị tích cực (ĐTTC) Bệnh viện Nhi Trung ương đã tiếp nhận khá nhiều trường hợp bệnh nhân viêm phổi nặng có kết quả dương tính với adenovirustrong dịch đường hô hấp với diễn biến lâm sàng râm rộ, tiến triển nặng nhanh, tỷ lệ tử vong cao. Việc xác định các yểu tố nguy cơ tử vong ở bệnh nhân viêm phổi nặng do nhiễm Adenovirus là rất quan trọng góp phân can thiệp điều trị và giảm tỷ lệ tử vong. Vì vậy chúng tôi thực hiện đề tàivới mục tiêu: 
Xác định một số yếu tố liên quan tới tử vong ở bệnh nhân viêm phổi nặng có nhiễm Adenovius tại khoa Điều trị tích cực Bệnh viện Nhi Trung ương.

\section{II. ĐỐI TƯỢNG VÀ PHƯƠNG PHÁP NGHIÊN CỨU}

2.1. Đối tượng: Bênh nhi được chẩn đoán viêm phổi nặng và rất nặngcó PCR Adenovirus (+) trong dịch đường hô hấpđang điều trị tại khoa ĐTTC bệnh viện Nhi Trung ương từ tháng 11/2016 đến 06/2018.

2.2.Phương pháp nghiên cứu: Nghiên cứu mô tả, có so sánh đối chiếu. Các triệu chứng lâm sàng, cận lâm sàng và kết quả điều trị được thu thập. 20.0

2.3. Xử lý số liệu: Theo phần mềm SPSS

* Phân tích đơn biến: để xác định rõ các yếu tố nguy cơ tử vong trong quần thể nghiên cứu.

* Phân tích đa biến: các yếu tố nguy cơ liên quan đến tử vong của viêm phổi nặng nhiễm Adenovirus được tìm thấy có ý nghĩa trong phân tích đơn biến, tiếp tục đưa vào phân tích hồi qui đa biến.

\section{KẾT QUẢ NGHIÊN CỨU}

\section{1. Đặc điểm chung của đối tượng} nghiên cứu

- Trẻ dưới 12 tháng tuổi chiếm $84,4 \%$, tỷ lệnam/nữ $=5 / 1,77,8 \%$ bệnh nhân vào khoa ĐTTC cần phải thở máy, trong đó có tới $21,1 \%$ cân thở máy cao tần, Thời gian thở ôxy và thở máy trung bình khá dài lần lượt là $8,1 \pm 6,8$ và $18,8 \pm 13,6$ ngày. $21,1 \%$ bệnh nhân phải lọc máu, 15,6 bênh nhân phải chạy ECMO

- Tỷ lệ tử vong của viêm phổi nặng nhiễm Adenovirus là $33,3 \%$

- Thời gian điêu trị tại khoa ĐTTC dài, trung bình 29,5 $\pm 25,2$ ngày.

3.2. Một số yếu tố dịch tễ, lâm sàng liên quan đến nguy cơ tử vong của viêm phổi nặng có nhiễm Adenovirus

Bảng 3.1. Liên quan giữa một số yếu tố lâm sàng với nguy cơ tử vong

\begin{tabular}{|c|c|c|c|c|}
\hline Yếu tố & $\begin{array}{c}\text { Nhóm sống } \\
(\mathbf{n = 6 0 )}\end{array}$ & $\begin{array}{c}\text { Nhóm tử vong } \\
(\mathbf{n = 3 0 )}\end{array}$ & $\begin{array}{c}\mathbf{O R} \\
\mathbf{( 9 5 \%} \mathbf{C l})\end{array}$ & $\mathbf{p}^{*}$ \\
\hline Tuổi $\leq 12$ tháng & 50 & 26 & $0,77(0,22-2,69)$ & 0,767 \\
\hline Giới nam & 49 & 26 & $0,68(0,2-2,4)$ & 0,549 \\
\hline Nguồn lâyy tại viện & 33 & 18 & $1,2(0,5-3,0)$ & 0,652 \\
\hline Sốc nhiếm khuần & 17 & 30 & $2,8(1,89-4,04)$ & 0,000 \\
\hline Suy dinh dưỡng & 11 & 13 & $3,41(1,29-9,02)$ & 0,011 \\
\hline Gan to & 22 & 25 & $8,64(2,89-25,8)$ & 0,000 \\
\hline Mức độ VP rất nặng & 42 & 30 & $1,7(1,4-2,08)$ & 0,001 \\
\hline BC viêm phối kẽ & 10 & 18 & $7,5(2,77-20,33)$ & 0,000 \\
\hline
\end{tabular}

Ghi chú: * $\chi^{2}$ test

Nhận xét: Các yếu tố lâm sàng như tình trạng sốc nhiễm khuẩn, suy dinh dưỡng, gan to,mức độ viêm phổi rất nặng, biến chứng viêm phổi kẽ là các yếu tố nguy cơ liên quan đến tử vong ở bệnh nhân viêm phổi nặng do nhiếm Adenovirus.

Bảng 3.2. Liền quan giữa một số chi số xét nghiệm với nguy cơ tử vong

\begin{tabular}{|c|c|c|c|c|}
\hline Chỉ số xét nghiệm & $\begin{array}{c}\text { Nhóm sống } \\
(\mathbf{n = ~ 6 0 )}\end{array}$ & $\begin{array}{c}\text { Nhóm tử vong } \\
(\mathbf{n}=\mathbf{3 0})\end{array}$ & $\begin{array}{c}\text { OR } \\
\mathbf{9 5 \%} \mathbf{C I}\end{array}$ & $\mathbf{P *}$ \\
\hline Giảm bạch cầu theo tuối & 5 & 8 & $4(1,2-13,6)$ & 0,028 \\
\hline Tăng bạch câuu theo tuối & 25 & 4 & $4,6(1,4-15,0)$ & 0,007 \\
\hline Giảm bạch câuu Lympho & 3 & 7 & $5,8(1,4-24,3)$ & 0,014 \\
\hline Hb $<100 \mathrm{~g} / \mathrm{l}$ & 37 & 28 & $8,7(1,9-40,03)$ & 0,02 \\
\hline APTT kéo dài $>37 \mathrm{~s}$ & 24 & 23 & $2,72(0,91-8,1)$ & 0,068 \\
\hline Procalcitonin $>0,5 \mathrm{ng} / \mathrm{ml}$ & 43 & 25 & $1,98(0,65-6,01)$ & 0,225 \\
\hline CRP $>50 \mathrm{mg} / \mathrm{l}$ & 18 & 13 & $1,8(0,72-4,4)$ & 0,21 \\
\hline Albumin $\leq 35 \mathrm{~g} / \mathrm{l}$ & 38 & 29 & $16,8(2,1-131,9)$ & 0,001 \\
\hline LDH $>450 \mathrm{U} / \mathrm{l}$ & 16 & 9 & $0,56(0,03-10,12)$ & 1,000 \\
\hline Lactat $>2,5$ & 10 & 14 & $3,4(1,26-9,26)$ & 0,014 \\
\hline P/F $\leq 200$ & 36 & 29 & $11,3(1,4-90,9)$ & 0,006 \\
\hline RL miê̂n dịch tế bào & 30 & 12 & $0,8(0,15-4,7)$ & 1,000 \\
\hline RL miến dịch dịch thế & 11 & 9 & $0,6(0,2-1,8)$ & 0,363 \\
\hline Đồng nhiêm & 34 & 20 & $0,68(0,27-1,7)$ & 0,409 \\
\hline
\end{tabular}


Ghi chú: * $\chi^{2}$ test

Nhận xét: Cácyếu tố cận lâm sàng làm tăng nguy cở tử vong ở bệnh nhân viêm phổi nặng do nhiễm Adenovirus gồm: Số lượng bạch cầu giảm theo tuổi, giảm số lượng bạch cầu lympho theo tuổi, $\mathrm{Hb}<100 \mathrm{~g} / \mathrm{l}$, Albumin $\leq 35$, Lactat $>2,5$; $\mathrm{P} / \mathrm{F} \leq 200$.

Bảng 3.6. Một số yếu tố lâm sàng, cận lâm sàng liên quan đến nguy cơ tử vong ở bệnh nhân viêm phổi năng nhiếm Adenovirus qua phân tích đa biến

\begin{tabular}{|c|c|c|}
\hline Chỉ số & OR (95\%CI) & $\mathbf{p}^{*}$ \\
\hline Gan to & $8,4(1,66-43,4)$ & 0,01 \\
\hline Suy dinh dưỡng & $4,3(0,95-19,42)$ & 0,058 \\
\hline $\begin{array}{c}\text { Biến chứng viêm } \\
\text { phổi kẽ }\end{array}$ & $2,3(0,6-8,2)$ & 0,202 \\
\hline $\mathrm{PaO}_{2} / \mathrm{FiO}_{2} \leq 200$ & $7,7(0,75-79,3)$ & 0,085 \\
\hline $\begin{array}{c}\text { Giảm bạch câu } \\
\text { theo tuổi }\end{array}$ & $\begin{array}{c}11,9 \\
(1,2-120,7)\end{array}$ & 0,035 \\
\hline $\begin{array}{c}\text { Tăng bạch câu } \\
\text { theo tuối }\end{array}$ & $\begin{array}{c}1,97 \\
(0,37-10,53)\end{array}$ & 0,426 \\
\hline Albumin $\leq 35 \mathrm{~g} / \mathrm{l}$ & $7,04(0,6-82,3)$ & 0,12 \\
\hline Lactat > 2,5 & $1,4(0,3-6,16)$ & 0,61 \\
\hline
\end{tabular}

Ghi chú: * phương pháp phân tích hồi quy đa biến

Nhận xét: Qua phân tích đa biến thấy các yếu tố nguy cơ độc lập liên quan đến tử vong của bệnh nhân viêm phổi nặng nhiễm Adenovirusbao gồm: bệnh nhân có gan to, giảm bạch cầu theo tuổi.

\section{BÀN LUÂ̂N}

Tổn thương phổi sau nhiễm Adenovirus cho thây có hiện tượngthâm nhiễm bạch cầu đơn nhân ở lớp dưới niêm mac và khoảng quanh mạch có thể dẫn đến tắc lòng phế quản, co thắt cơ trơn phế quản thường xảy ra trong phản ứng viêm này. Các tổn thương ở phế bào týp II dẫn đến giảm sản xuất surfactant, hình thành màng hyaline và phù phổi. Các nghiên cứu giải phẫu bệnh cũng chỉ ra sự phá hủy lông mao biểu mô khí quản và quá phát các tế bào biểu mô đường hô hấp khác với sự hiện diện của thể vùi trong nhân. Trong viêm phổi nặng giải phẫu bệnh có hình ảnh viêm hoại tử phế quản, tiểu phể quản và Cùng với đó là sự xâm nhập của tế bào đơn nhân, hoại tử biểu mô, phá hủy lớp màng hyaline. Hậu quả là xẹp phổi, phù phổi kẽ và rối loạn thông khí - tưới máu gây ra thiếu oxy máu đáng kể đi kèm với tắc nghẽn đường thở [3], [4]. Trong 90 bệnh nhân được chẩn đoán là viêm phổi do Adenovirus phải điều trị tại khoa ĐTTC, hầu hết các bệnh nhânphải hỗ trợ hô hấp bằng thông khí nhân tạo, đặc biệt có tới $21,1 \%$ bệnh nhân cần phải thở máy cao tần. Mặc dù đã phải thực hiện cùng lúc nhiêuu biện pháp can thiệp điều trị như: lọc máu $(21,1 \%)$, ECMO $(15,6 \%)$ nhưng tỷ lệ tử vong ở trẻ viêm phổi do Adenovirus trong nghiên cứu của chúng tôi là rất cao $33,3 \%$. Kết quả này cao hơn nhiều so với nghiên cứu của Đào Minh Tuấn là 12,5\% [5], Chang Yu [3] và Chin-Yin Lai là 22\% [6]. Tuy nhiên có sự khác biệt về quần thể nghiên cứu, đối với nhóm nghiên cứu của chúng tôi là bệnh nhân nhập khoa ĐTTC với những đặc điểm chính; tuổi dưới 12 tháng,tình trạng sốc nhiễm khuẩn, suy dinh dương, gan to, mức độ viêm phổi rất nặng, biến chứng viêm phổi kẽ, giảm bạch cầu theo tuổi, tăng bạch cầu theo tuổi, giảm bạch câu lympho theo tuổi, Albumin $\leq$ $35 \mathrm{~g} / \mathrm{l}$, tình trạng rối loạn oxy hóa $\mathrm{P} / \mathrm{F}<200$, Lactat $>2,5$ là những yếu tố có ảnh hưởng tới nguy cơ tử vong ở bệnh nhân viêm phổi nặng nhiễm adenovirus[7], [8] và trong phân tích đ̛ơn biến của chúng tôi. Tuy nhiên khi thực hiện phân tích đa biến kết quả chỉ ra hai yếu tố tiên lượng độc lập là gan to và số lượng bach cầu hạt giảm so với lứa tuổi. Gan to trong viểm phổi nặng do Adenovirus có thể ảnh hưởng bởi nhiều yếu tố như tổn thương gan do Adenovirus, thông khí áp lực dương, do phản ứng viêm hệ thống, vấn đề này cần được nghiên cứu thêm. Đối bệnh nhân có giảm số lượng bạch câu tuy tỷ lệ không cao là 14,4\%, nhưng khi số lượng bạch cầu giảm làm cho cơ thể không có khả năng sinh miễn dich chống lại các tác nhân gây bệnh khác, đồng thời cũng phả ánh tình trạng nhiễm khuẩn nặng ở bệnh nhân nhiễm Adenovirus hoặc đồng bội nhiễm vi khuẩn và virus khác, trong nghiên cứu của chúng tôi có tới $78,9 \%$ bệnh nhân có hội chứng đáp ứng viêm hệ thống, 43,3\% bệnh nhân đồng bội nhiễm một loại vi khuẩn hoặc virus khác. Các nghiên cứu cũng chỉ ra cây máu dương tính, tình trạng đồng nhiễm hoặc bội nhiễm thêm vi rút và/hoặc vi khuẩn (đặc biệt Klebsiella và Pseudomonas) là nguyên nhần gầy tử vong cao ở những bệnh nhân viêm phổi nhiễm Adenovirus [7],[9].

\section{KẾT LUẬN}

Tỷ lệ tử vong ở bệnh nhân viêm phổi nặng có nhiễm Adenovirus là 33,3\%. Giảm số lượng bach cầu hạt theo lứa tuổi và gan to là hai yểu tố độc lập tiên lượng tử vong.

TÀI LIỆU THAM KHẢO

1. Jain S, Williams DJ, Arnold SR, et al. (2015). Community-acquired pneumonia requiring hospitalization among U.S. children. N Engl J Med, 372:835.

2. Cherry, R.D. Feigin, J.D. Cherry et al. (2009). Textbook of pediatric infectious diseases. 6th ed. 
WB Saunders, Philadelphia, 1843-1862.

3. Chuang $\mathrm{Yu}$, Chiu CH, Wong KS et al. (2003). Severe adenovirus infection in children. Journal of Microbiology, Immunology, 36(1):37-40.

4. Joseph P. L, Michael F, Marcela E.(2011). Adenovirus. Seminars in respiratory and critical care medicinr, 32 (4), 496

5. Đào Minh Tuấn, Nguyễn Thị Ngọc Trân. (2017). Nghiên cứu môt số đăc điểm dich tể và lâm sàng của viêm phế quản phổi do Adenovirus tại Bệnh viện Nhi Trung ương từ tháng 1 đến tháng 6 năm 2016 đến năm 2017. Y học thực hành tập 739- số 10.

6. Chen-Yin Lai. (2013). Adenovirus Serotype 3 and 7 Infection with Acute Respiratory Failure in
Children in Taiwan, 2010-2011. PLOS Genetics. January 10.17:196

7. Du Fang. (2013). Mixed infection and risk factor in children with severe adenovirus pneumonia. Children's Hospital of Chongqing Medical Univerity, China, 15(5): 375-8

8. Huang M, Luo R, Fu Z. (2017). Risk factors for poor prognosis in children with severe adenovirus pneumonia. Zhongguo Dang. Chinese Journal of Contemporary Pediatrics, 19(2): 159-162.

9. Le Thanh Hai, Hoang Ngoc Thach, Ta Anh Tuan, et al. (2014). Adenovirus Type 7 Pneumonia in Children Who Died from Measles-Associated Pneumonia, Hanoi, Vietnam. 22(4):687-90

\section{ĐÁNH GIÁ ĐIỂM MELD, MELD Na Ở BÊ̂NH NHÂN XƠ GAN CÓ BIẾN CHỨNG}

\section{TÓM TẮT}

Mục tiêu: Đánh giá thang điểm MELD, MELD Na ở BN xờ gan có biến chứng. Đối tương, phương pháp: Nghiên cứu mô tả tiến cứu tại khoa Tiêu hóa, bệnh viện Bạch Mai từ 07/2019 đển 03/2020. Đối tượng nghiên cứu được chẩn đoán xơ gan và có biến chứng. Kết quả và kết luân: Có 387 BN thỏa mãn tiêu chuẩn. Điểm MELD, MELLD Na trung bình ở nhóm BN có XHTH tương ứng là $(13,15 \pm 5,15),(15,05 \pm$ $5,8)$ thấp hơn nhóm $\mathrm{BN}$ không có $\mathrm{XHTH}(21,03 \pm$ $7,06),(23,78 \pm 7,51) ; p<0,001$ và không có ý nghĩa dự báo biến chứng với AUC < 0,5. Điểm MELD, MELD Na trung bình ở nhóm BN có bệnh não gan $(21,16 \pm$ $7,85)$, (23,76 $\pm 7,94)$ cao hơn nhóm BN không có bệnh não gan $(12,93 \pm 4,57),(14,85 \pm 5,46) ; p<$ 0,001 và có ý nghĩa dự báo yếu về biến chứng bệnh não gan với AUC < 0,7े. Điểm MELD, MELD Na trung bình ở nhóm BN có NTDCT $(18,06 \pm 6,82)$, $(20,8 \pm$ $7,32)$ cao hơn nhóm BN không có NTDCT $(14,15 \pm$ $6,15)$, $(16,11 \pm 6,82) ; p<0,001$ và cóý nghĩa dự báo biến chứng NTDCT với AUClà 0,701 và 0,725.Điểm MELD, MELD Na trung bình ở nhóm BN có HCGT $(27,94 \pm 9,13),(30,37 \pm 8,39)$ cao hơn nhóm bệnh nhân không có HCGT $(14,08 \pm 5,56),(16,13 \pm 6,38)$; $p<0,001$ và có ý nghĩa dự báo biến chứng HCGT với AUC là 0,905 và 0,901 . Điểm MELD, MELD Na trung bình ở nhóm $B N$ có từ hai biến chứng trở lên $(20,23 \pm$ $8,89)$, $(22,55 \pm 8,69)$ cao hơn nhóm BN chí có môt biến chứng $(13,53 \pm 5.04),(15,54 \pm 6,04) ; p<0,001$ và có ý nghĩa dự báo số lượng biến chứng với AUC là 0,744 và 0,739 .

Tư khóa: MELD, MELD Na, xơ gan có biến chứng.

\footnotetext{
${ }^{1}$ Trường Đại học Y Hà Nội

${ }^{2}$ Bênh viên Bach Mai

Chịu trách nhiệm chính: Nguyễn Thị Oanh

Email: oanhblouse@gmail.com

Ngày nhận bài: 22.10.2020

Ngày phản biện khoa họ: 30.11 .2020

Ngày duyệt bài: 10.12 .2020
}

Nguyễn Thị Oanh ${ }^{1}$, Nguyễn Thị Vân Hồng1,2

\section{SUMMARY}

EVALUATION OF THE MODEL FOR END STAGE LIVER DISEASE (MELD) SCORE, THE MELD SODIUM SCORE IN CIRRHOSIS PATIENTS WITH COMPLICATIONS

Aims: To evaluate the value of the MELD, MELD $\mathrm{Na}$ score in patients with cirrhosis and its complications. Subjects and methods: The prospective descriptive study was conducted at Department of Gastroenterology Bach Mai Hospital from July 2019 to March 2020. Research population: patients werediagnosed with cirrhosis and complications. Results and conclusion: There were 387 patients were recruited in our study. Mean MELD, MELD $\mathrm{Na}$ scores in the group of patients with GI bleeding were (13.15 \pm 5.15), (15.05 \pm 5.8), respectively which were lower than the group of patients without GI bleeding $(21.03 \pm 7.06),(23.78 \pm$ $7.51) ; p<0.001$ and it is not significant to anticipate complications with AUC <0.5. Mean MELD, MELD Na scores in the group of patients with hepatic encephalopathy were $(21.16 \pm 7.85),(23.76 \pm 7.94)$, respectively, which were higher than the group of patients without hepatic encephalopathy (12.93 \pm 4.57), (14.85 \pm 5.46); $p<0.001$ and it's slight significance to predict hepatic encephalopathy complications with AUC <0.7. Mean MELD, MELD Na scores in the group of patients with spontaneous bacterial peritonitis (SBP) were (18.06 \pm 6.82$)$ and $(20.8 \pm 7.32)$, respectively, which were higher than the group of patients without SBP $(14.15 \pm 6.15)$, $(16.11 \pm 6.82) ; p<0.001$ and this is of significance to predict SBP complications with AUC were 0.701 and 0.725 . Mean MELD, MELD Na scores in the group of patients with hepatorenal syndrome (HRS) were $(27.94 \pm 9.13)$ and $(30.37 \pm 8.39)$, which were higher than the group of patients without HRS (14.08 \pm $5.56),(16.13 \pm 6.38) ; p<0.001$ and it is of significance to anticipate HRS complications with AUC 